\title{
TOWARDS AMBIENT SCHOOLING
}

\author{
A European Research and Development Agenda
}

Frans Van Assche

European Schoolnet

Abstract: Ambient schooling creates a schooling environment 'surrounding' the pupil in a non-intrusive way. It is part of a ten-year vision of ministries of education in Europe in response to a changing information society. The realization of this vision will require substantive research and development. Critical success factors are the provision of the right infrastructure, the implementation of a school-grid allowing exchange of data and services beyond content, intelligent support for the learning process also in terms of knowledge building, better support for teachers, a different way of developing supporting tools, adaptation of buildings, and a clear migration strategy.

Key words: E-learning systems; learning technology; ambient intelligence; Europe; ambient schooling; grid; knowledge building; personalized learning.

\section{AMBIENT SCHOOLING}

The concept for ambient schooling was developed by the European Schoolnet as part of a ten-year vision of 26 ministries of education in Europe. It should be understood in context of a changing European society. As Matti Sinko, Finnish Ministry of Education observes ${ }^{1}$ :

"The whole notion of school used to be based on the idea that it is easier to organise learning when it takes place separated from the distractions of everyday social and business life. In recent years this paradigm has been completely changed in favour of increased and intensified communication and interaction between the school and the surrounding community and society. New concepts like a school without walls or a virtual school have emerged and become popular at least in school development rhetoric. Parents used to leave their children to school for 
education, now parents and other adult members from various walks of life are more and more encouraged to assist in tutoring and even in teaching. And all this takes place not only in the classrooms and homes but in libraries, leisure centers and other public places, in shops, in workplaces, and businesses. This all makes learning much more natural, flexible and less distanced from realities of life, but at the same time it addresses more complex and genuine problems of life."

The re-organization of learning has been largely overlooked, even though there has been a recognition that national ICT strategies will only achieve their objectives once there is a "fundamental change in the way learning is constructed within schools" $"$. In 2004, the vision still remains more a part of what Sinko calls "school development rhetoric" than something that is visible in the majority of Europe's schools. Moreover, the original vision is under threat as society begins to question the return on investment for ICT in schools. There are signs of a 'disconnect' between ICT use in and out of schools with pupils being increasingly critical of the former ${ }^{3}$. Most worryingly, scenarios are seriously being considered where ICT simply fails to deliver and there is "technology meltdown". In short, having failed to address fundamental issues related to the re-organization of learning, the future of e-learning for schools in the Information Society is being questioned.

Against this background the concept of ambient schooling is developed and represents a Copernican revolution. While in the past ICT has been used to bring content and services to schools, ambient schooling brings the school to the learner. Ambient means 'surrounding' and refers to the fact that a learner is surrounded by his/her school. This should be done in a nonintrusive way. The availability of the 'school functionality' should be managed and it can be turned off, much like a mobile phone.

Ambient schooling is a dynamic process where, via the appropriate use of advanced technologies, pupils are supported as they continue to learn in formal institutions but are presented with increasing opportunities to learn in the home, libraries, museums and the wider community. New, nextgeneration technologies are particularly required for ambient schooling in order to help pupils to navigate between a variety of learning environments and to ensure a high degree of interoperability between the learning services provided by each of the settings. 


\section{INFRASTRUCTURE FOR AMBIENT SCHOOLING}

The key infrastructure components for ambient schooling are mobile technology, broadband, and one-on-one, i.e. one computer per pupil.

Mobile technology must involve ubiquitous wireless access and new devices. Typically these devices will be light and with adequate capabilities in terms on wireless communication. However, with the advent of organic light emitter technology, the shape may be quite different from the tablet PCs, palmtops or smart phones we know now.

Broadband technology provided must go all the way to the device that the user is using. In addition it will need to be wireless with ubiquitous access points much like mobile phones work today.

While schools have equipped some of their classrooms with computers, their use remains limited. Typically computers are only used when pupils are in the computer lab. Extensive research ${ }^{5,6}$ has shown that (a) when pupils can 'own' their personal computer the usage increases dramatically and (b) along with the increased use, the learning is more effective. Currently only small computers such as palmtops are affordable. But even when prices drop, the mere fact that handhelds are so portable makes them an interesting choice. In the foreseeable future, personal computers will become a commodity and pupils will start to use their own portable devices in and out of the school premises.

\section{OBJECTS FOR AMBIENT SCHOOLING}

Currently, there exist quite a number of learning object repositories and recently the first federated brokerage system for learning objects using asynchronous messaging in a heterogeneous environment was demonstrated $^{7}$. However, in order to realize the ambient schooling vision, interoperability of other data and services is required. For instance, where can a teacher or pupil in France find an expert of cartography of the middle ages, or a hotseat ${ }^{1}$, or an interesting project, or a school in Queensland for twinning, etc. How can a user propagate a discussion to other forums, if s/he does not get an answer in his or her own environment?

A hotseat is a mechanism where an expert is available for a specific period of time (e.g. a week) to answer queries from students. This is often done in an asynchronous way. The experts answers when s/he has time. 
In technical terms this means that data, content, tools and services should be shared on a European and even global level. Four areas are of particular interest: Learning Content, Learning Management, Learning communities, and School management.

\section{Learning content}

Standards and specifications exist to support various aspects of the exchange of learning objects in an effective way. The IEEE LOM is a standard issued by an accredited standardization body and supports the description of Learning Objects. A subset of the LOM can also be used for the description of Learning Assets. For packaging content, the IMS content packaging specification can be used. The Dublin Core Metadata Initiative (DCMI) specification will support the description of other resources.

\section{Learning management}

In the field of learning management and learning content management we are dealing with objects such as student, learning progress, assessment, activity flow, etc.

Learning communities.

In the field of learning communities we are dealing with announcements of events (such as workshops, conferences, chats), users, user groups, schools, special interest groups, networks, news, projects, bulletin boards. Existing standards and specifications in this field are: vCard, vCalendar, RSS, NewsML.

School management.

In the field of school management we are dealing with issues such as transportation, libraries, student attendance, meals, gradebooks, human resources, financial, etc. In this area the specification of the Schools Interoperability Framework (SIF) and its adaptation to the European situation as developed in the OASIS project ${ }^{2}$ and the work of CEN/ISSS WSLT $^{3}$ is of great importance.

\section{THE SCHOOLGRID}

During the last years we have seen the emergence of grid architectures from computing grids to data and application grids. For ambient schooling it is especially the latter kind of grid which is important. The schoolGRID can be seen as a further evolution of learning object brokerage systems currently being developed around the world. As in a LO brokerage system, the

\footnotetext{
${ }^{2}$ http://oasis.cnice.mecd.es/

${ }^{3} \mathrm{http}: / /$ www.cenorm.be/isss/Workshop/lt/
} 
purpose is to match demand with supply. However the data and services requested and delivered extend far beyond content and include the diverse object types as elaborated in section 3 .

\subsection{Architecture}

At the heart of the SchoolGRID architecture (see figure 1) is a catalogue describing the services available. The catalogue is more than just a UDDI directory. The catalogue should contain at least:

- What service is delivered and under what conditions. This would include a textual description of the service, costs, rights, quality assurance measures from the provider, etc

- Where to access the service

- In what format the service can be requested. This would include the API and how to use it

- In what format the results are obtained.

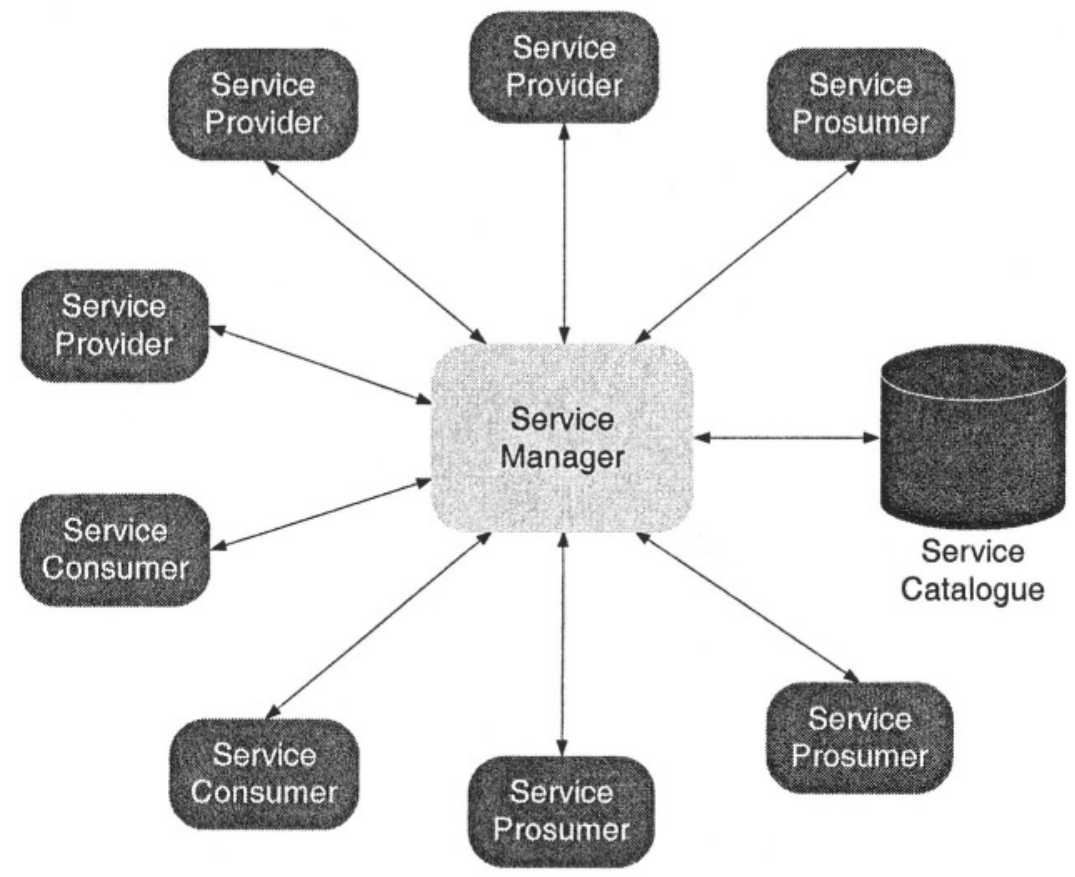

Figure 1. The Learning Grid architecture

As an example in the learning resource area, service prosumers (a service provider that is at the same time a service consumer) could be LMSs, 
LCMSs; service providers could be learning object repositories; and service consumers could be some eLearning portals. An example service is the discovery and delivery of learning objects. The learning objects are organized in collections and the catalogue describes the collections. This fits well with the concepts of Collection Level Descriptors as developed in the field of metadata. A collection may be distributed over more than one repository and a repository may hold more than one collection (even several collections that are overlapping).

The important point is that collection level descriptions not only describe the collection as a whole but that many data elements will be inherited by the elements of this collection. As an example take the data element 'Quality Selection Policy' that describes the selection policy that is followed for resources to be included in the collection. By doing so it is not necessary to have the quality selection policy repeated over and over again with each resource. Not only does this facilitate the initial metadata tagging but also this ensures that changes to the policy are dealt with consistently.

Further work on collection level descriptors should be directed towards unification and standardization. While application profiles are necessary in order to meet the needs of the different communities, this is not so much the case for collection level descriptors.

A second example in the area of community objects goes as follows: in Austria, Switzerland, Northern Italy, and Germany are lively discussion groups dealing with physics. The discussion group in Austria is discussing something on which they would like to have a second opinion. The SchoolGRID would allow any member (teacher) of this discussion group to search whether there are other discussion groups of teachers discussing physics in German. After having identified such discussion groups, the Austrian teacher can post his/her question to a selected number of other discussion groups. Alternatively, this selection process could be automatic.

\subsection{Services}

From the examples it should be clear that the SchoolGRID will provide different kinds of services, but a large majority of these will be discovery services, providing answers to questions such as: are there interesting events, calls for proposals, projects, schools, LOs, etc. These discovery services may follow a drilling down pattern. For example, there is first a search of the catalogue to determine whether there are any interesting collections, and then a federated search is launched to search in these collections.

The SchoolGRID provides intelligent brokerage functionality in addition to a number of central services. This brokerage functionality is hierarchically 
structured. For example, take the search and exchange of learning objects. This can happen at different levels. LOs can be exchanged at the school level, at the regional level, at the national level, and at the international level. When a teacher using his/her own VLE would like to search outside his/her own school environment s/he should be able to do so either as the result of a conscious choice or automatically. In any case, the technical and rights negotiations between the different levels and the partners should be entirely transparent. Likewise, this teacher may decide to make a learning object available at a regional level. The regional administrator could decide to publish it at the country level, and the country administrator could decide to make it available at the European level.

While a single SchoolGRID will suffice in Europe, it is unlikely that it will be the only educational GRID in the world or even in Europe. Therefore the SchoolGRID should also be able to talk to the other GRIDs and exchange catalogue information such that services can also be exchanged. Moreover, because of performance issues, any such GRID will require mirroring of its basic services.

\section{AMBIENT LEARNING}

Ambient schooling will increasingly take place within an environment that can be tailored on-the-fly with regard to the personal learning style, preferences, competencies, dynamic learner profile, or learning needs of the pupils, and taking into account the available tools, digital resources, and human support. While customization possibilities exist in most currently available VLEs, adaptation of the learning process poses additional, major challenges.

The learning process in the ambient schooling vision is specific to any human learner, is suspended and resumed at his/her will, and may appear in quite different forms that adhere to the educational plan, but adapt to the progress of the learner, to his/her options, to the recommendations of other stakeholders, and to the availability of humans and digital resources.

One of the key components is this process is the Adaptive Learning Unit (ALU) that represents the "Educational Plans". While these might be represented by, e.g., a human teacher or even the learner, the aim is to support extensive reuse of digitally encoded educational plans that carry the expertise of eminently talented human educational experts. ALUs represent digitally encoded educational expertise, carry the rules for composing and organizing learning activities, and use descriptive information for decision making. Typical descriptive information is related to humans (e.g., current and desired competencies and many categories of preferences) and to digital 
resources (i.e. metadata for all kinds of digitally encoded expertise like learning objects, educational plans, information and resource brokering services, etc.). The ALU approach is capable of bringing diverse educational concepts into action, like IMS Learning Design but constructed on-the-fly.

For authoring ALUs, one should make extensive use of "lessons learnt" in formats of templates, wizards (for frequently used genres) and even generators (for regularly used and well approved genres) will provide effective support to authors who lack specific IT expertise. Authoring may be influenced by feedback from the users as part of a knowledge building process.

\section{KNOWLEDGE BUILDING IN AN AMBIENT SCHOOLING CONTEXT}

Knowledge building in an ambient schooling context deals with (a) further research on the knowledge building process and its support through ICT beyond current practice in computer supported collaborative learning (CSCL), (b) new ways of knowledge building assessment, (c) investigating the harnessing of new devices, and (d) shaping the supporting environment for the specific needs of ambient schooling. Recent research shows that ICT enhanced learning as implemented currently has a number of shortcomings. Scardamalia and Bereiter already in 1992 in their knowledge building theory proposed that schools should be restructured towards knowledge-building organizations, in which students and teachers participate in the construction of collective knowledge as in professional research groups where the object of activity is solving knowledge-problems. Currently we are only at the beginning of supporting this vision in schools through implementation of ICT.

\section{ADVANCED FEATURES FOR TEACHERS}

While ICT in education yields many benefits, they also come at a cost especially for the teacher. Currently, the cost for the teacher (measured in additional workload) frequently cancels out the benefit he or she perceives. The ambient schooling vision puts high emphasis on making the work of the teacher as easy as possible. The technologies used should therefore provide utmost transparency and user-friendliness for teachers and must be affordable and easily maintained/assimilated by the institutions that use 
them. This is well in line with the view of the ISTAG group ${ }^{4}$ which states that:

"[Ambient Intelligence] system will "know itself, adapt easily to the needs to the individual, actively look for ways to optimize its workings, be able to protect itself and recover from routine malfunctions etc. - all with a view towards making life easier for the individual who is engaged with the system but may not even know that s/he is consciously 'interacting' with it"

At least the following three research areas should be addressed. First, authoring support should improve or be newly developed, including for the earlier expounded ALUs. The required skills of authors should reflect their expected range of expertise. As currently only few experts have noteworthy experience with Educational Modeling Languages and IMS Learning Design, measures should be taken that will reduce the construction effort. Among these measures should be well-tested templates and wizard support in the construction of executable educational plans, based on the recognition of a variety of learner profiles. The necessary tools to create and modify these digital resources in various ways are needed.

Second, new ways should be promoted to ease the burden of meta-data tagging as much as possible including automated tagging based on semantic analysis, predictive tagging, tagging by placement in a repository taxonomy, and other techniques.

Third, concepts and tools for ontology mapping should be developed. Metadata are currently in a form that does not fully reflect the needs of teachers and pupils. For example, teachers and pupils do not instinctively think in the terms of the value spaces of metadata. Ideally they should be able to develop their own system of concepts (ontology) or choose some they like and have their concepts automatically mapped to the available metadata or metadata templates. By doing so, ontologies for the semantic web can also be provided.

\section{AN OPEN FRAMEWORK}

When providing ICT tools for supporting the field of learning, education, and knowledge building one has to deal with two conflicting requirements: diversity and standardization. Firstly, there is the requirement for many different kinds of support for different communities and categories of users. 
The need for a diverse range of support is due to the large diversity of scenarios that is, in turn, dependent on the type of application, on personal and institutional habits, and on broader social and cultural factors. Secondly, there is a strong requirement for extensive interoperability across these communities.

The concept of an Open Component Framework proposed here is well able to comply with these seemingly conflicting requirements, mainly by decomposing platform functionalities to very fine-grained components. Requirement specifications can be derived from the analysis of a number of important scenarios for ambient schooling. Based on these specifications, components can be designed and implemented as needed. Components comprise various information object types, information processing software, interfaces, and protocols. The separation of component specification and technology binding is crucial for the 'longevity' of the framework. Following this approach a VLE can be built by assembling components. As VLE providers may provide their own versions of aggregations, in order to add value for specific clients and users, (using, e.g., an avatar for humancomputer interaction), many VLEs will be able to co-exist.

The implementation should be open in two respects. Firstly the framework should be open for people to join in by picking the services they need and using them. Secondly, the implementation of the component framework should be open source to a large extent. The advantage of open source is that it fosters a basis of trust for a growing user community, a large experimenting community for fast feedback and high productivity, and a sustainable community infrastructure that on the long term is not dependent on a small group of developers. In this way, it allows any tailoring as needed (see for instance also the IDA study ${ }^{8}$ ).

\section{FURTHER IMPLEMENTATION ISSUES}

While a lot of the learning will also happen outside the school buildings, the implementation of the ambient schooling vision will probably require other building structures or at least other uses of existing buildings. An interesting study was done in a small school in Iceland where, due to inaccessibility, a lot of the learning was organized outside the classroom. The classical notion of a classroom was abandoned in favor of more flexible study and meeting places.

One of the major challenges will be the organizational change that the implementation requires. Scenarios and models for implementing nextgeneration technology combined with strategies for change management and 
the re-organization of learning in schools and other settings are required. Key actions are:

- To monitor and describe trends and issues in national education systems across Europe as the societal needs concerning education, as well as technological and organizational possibilities will change. The way that national educational systems are dealing with it needs to be closely followed and described.

- To provide demonstrations of implemented models of significant organizational change in schools and learning that takes place in a variety of settings (schools, the home, museums, libraries and the wider community), underpinned by next generation technologies.

- To evaluate progress in these areas against benchmarks for each of the participating municipalities given their current level of ICT implementation at the start of the demonstration phase.

- To establish an in-service teacher training initiative and associated materials related to change management, taking into account the wider visions of the role of the teacher in the ambient school, using online services, content and collaborative tools developed by Release.

- To describe and analyze current models of schooling and develop roadmaps for change to ambient schooling. When new models suitable for ambient schooling have been developed, the current state of schooling needs to be understood in order to develop the necessary roadmaps for teachers, schools, policy makers, and industry.

The ambient schooling vision must include the strong possibility that the provision of infrastructure will become less of a State responsibility as pupils increasingly carry their own personal information/communication device Though measures will need to be taken to support the 'have-nots' and combat a digital divide. Currently pupils in Europe are typically required to turn off their mobile phones when they enter the school but this will soon become nonsensical. Why should pupils turn off their next generation PDA/smart phones/computers at the school gates in order to use (probably older/inferior) equipment provided by the State solely for use in the classroom?

Ambient schooling will only succeed if social change and leveraging the increasing ubiquity of computing devices and networks is properly recognized.

\section{ACKNOWLEDGMENT}

I wish to thank Jim Ayre, Rolf Lindner, and Ulf Lundin for their contribution to the development of the ideas presented in this paper. 


\section{REFERENCES}

1. Matti Sinko, Ministry of Education Finland, Tips for Making an Educational ICT Project a Success, 1999, http://np.ipc.lt/projektai/01-02_en.html.

2. Furlong J, Furlong R, Facer K and Sutherland R, The National Grid for Learning: $a$ curriculum without walls? Cambridge Journal of Education 2000 30(1), p102.

3. Downes, T., and Reddacliff, C. Young Children Talking about Computers in their Homes. in Papers of the Australian Computers in Education Conference, Sydney, 1996.

4 David Wood, The THINK Report: Technology in Education Futures for Policy, EUN, February 2002, http://eminent.eun.org/THINK_FULL_DRAFT_2pp.doc.

5 Soloway, E., Norris, C., Blumenfeld, P., Fishman, B., Krajcik, J., Marx, R. Log on Education Column: Palm-Computing Devices are Ready-at-Hand. Communications of the ACM, (June 2001).

6. Norris, C., Soloway, E., and Sullivan, T. Examining 25 years of technology in U.S. education. Communications of the ACM (2002) 45(8): 15-18.

7. Van Assche F., Massart D., Federation and Brokerage of Learning Objects and Their Metadata, Proceedings of the I-CALT 2004 conference, to appear.

8. POOLING OPEN SOURCE SOFTWARE. An IDA Feasibility Study. Interchange of Data between Administrations, European Commission, DG Enterprise, June 2002, http://europa.eu.int/ISPO/ida/export/files/en/1115.pdf, page 7. 